\title{
A Socio-Rhetorical Interpretation of the Letter to Philemon in Light of the New Institutional Economics
}

An Exhortation to Transform a Master-Slave Economic Relationship into a Brotherly Loving Relationship

[Eine sozio-rhetorische Interpretation des Briefs des Paulus an Philemon im Licht der Neuen Institutionenökonomik. Eine Ermahnung, die ökonomische Beziehung zwischen Herrn und Sklaven in eine der brüderlichen Liebe zu verwandeln.]

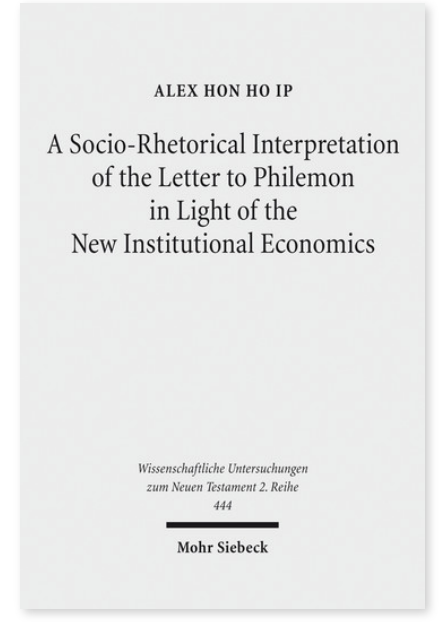

2017. XVIII, 246 Seiten. WUNT II 444

ISBN 978-3-16-155583-1

DOI 10.1628/978-3-16-155583-1

eBook PDF 99,00€

ISBN 978-3-16-154728-7

fadengeheftete Broschur 99,00€
Veröffentlicht auf Englisch.

In dieser Studie erörtert Alex Hon Ho Ip, dass Paulus, als er Philemon bezüglich Onesimus schrieb, nicht in erster Linie im Sinn hatte, die beiden als Herr und Sklave wieder zusammenzuführen, wie allgemein vermutet wird, sondern dass Onesimus als geliebter Bruder vor Christus angenommen würde. Indem er die innere Struktur der Briefe untersucht, zeigt der Autor, dass es das Hauptinteresse des Paulus war, Philemon und Onesimus in brüderlicher Liebe zu versöhnen. Das intertextuelle Gewebe offenbart Paulus' theologische und ethische Überlegungen über die Liebe, welche die Basis der Beweisführung des Apostels sind. Alex Hon Ho Ip rekonstruiert anhand des Denkansatzes der Neuen Institutionenökonomik die wirtschaftliche Beziehung zwischen Sklaven und Herrn und ist dadurch in der Lage, die ursprüngliche Beziehung zu verdeutlichen, gegen die Paulus sich aussprach. Vor diesem Hintergrund liegt der Fokus darauf, den Brief erneut zu lesen und zu vernehmen, wie die Rhetorik des Paulus zu einer neuen Beziehung zwischen Onesimus und Philemon ermahnt.

Alex Hon Ho Ip Born 1973; 1995 B. Econ.; 1997 M. Econ.; 2010 M. Div.; 2014 PhD; since 2016 Assistant Professor in New Testament, Chung Chi Divinity School, Chinese University of Hong Kong. https://orcid.org/0000-0001-7938-4286

Jetzt bestellen:

https://mohrsiebeck.com/buch/a-socio-rhetorical-interpretation-of-the-letter-to-philemon-in-light-of-the-new-institutionaleconomics-9783161555831?no_cache=1

order@mohrsiebeck.com

Telefon: +49 (0)7071-923-17

Telefax: +49 (0)7071-51104 